\title{
Special issue on nonlinear fractional differential equations and their applications in honour of Ravi P. Agarwal on his 65th birthday
}

\author{
Dumitru Baleanu
}

Received: 17 January 2013 / Accepted: 21 January 2013 / Published online: 29 January 2013

(C) Springer Science+Business Media Dordrecht 2013

Professor Ravi P. Agarwal received his Masters in Science from Agra University in 1969, and then his Ph.D. in Mathematics from the Indian Institute of Technology, Madras, India in 1973.

Since then, he has become one of the reference researchers in the field of Nonlinear Differential Equations. He has authored over 1000 papers in collaboration with a large number of colleagues from various countries all over the world. He has published more than 25 monographs and books. Professor Ravi P. Agarwal is the Editor-in-Chief of four journals and serves on the editorial board of over 40 International journals. His work has been cited over 5000 times, which distinguishes him as one of the most cited professors in his field. At present, Professor Ravi P. Agarwal is Chair of the Department of Mathematics, Texas A\&M University-Kingsville, USA.

Over the last 40 years Professor Ravi P. Agarwal has played a leading role in many other branches of mathematics such as Difference Equations, Fixed Point Theory, General Inequalities and Numerical Analysis and their Applications. His seminal recent work on several topics has had an impact in the community of mathematics, as well as in the field of applied sciences. His points of view about science and mathematics in particular are unique and his multidis- ciplinary knowledge helps propose new solutions for some of the big provocations of science.

The present special issue on new challenges in the field of nonlinear fractional differential equations and their applications is published in the honor of his 65th birthday. This collection is a reflection of his immense creative capacity and it reflects only a small portion of his highly relevant work in this field.

Professor Ravi P. Agarwal is not only a huge talent in Applied Mathematics but also a charming individual who has served as a role model for many generations of scientists across the world.

On this occasion, we wish Professor Ravi P. Agarwal the best of health and happiness in the years ahead, and we count on his prolific scientific activities in the future.

Dumitru Baleanu, Donal O’Regan and Juan J. Trujillo

D. Baleanu ( $\varangle)$

Cankaya University, Ankara, Turkey

e-mail: dumitru@cankaya.edu.tr 